\title{
A Survey of Hard Ticks (Ixodidae) on Cattle and Goats in a Wildlife-Livestock Interface Ecosystem at Mikumi National Park, Tanzania
}

\author{
Donath Damian 1,3 *, Modester Damas ${ }^{1}$, Jonas Johansson Wensman², Mikael Berg ${ }^{3}$ \\ ${ }^{1}$ Department of Molecular Biology and Biotechnology, University of Dar es Salaam, Dar es Salaam, Tanzania \\ ${ }^{2}$ Section of Ruminant Medicine, Department of Clinical Sciences, Swedish University of Agricultural Sciences, \\ Uppsala, Sweden \\ ${ }^{3}$ Section of Virology, Department of Biomedical Sciences and Veterinary Public Health, Swedish University of \\ Agricultural Sciences, Uppsala, Sweden
}

*Corresponding Author: Donath Damian, Department of Molecular Biology and Biotechnology, University of Dar es Salaam, Dar es Salaam, Tanzania, Section of Virology, Department of Biomedical Sciences and Veterinarv Public Health. Swedish Universitv of Agricultural Sciences. Uppsala. Sweden

\begin{abstract}
Ticks as obligate blood-sucking ectoparasites, cause reduction in livestock weight, limit livestock production, induce anemia, cause irritation, some of the species have toxins that cause paralysis, and are vectors of different pathogens. There has recently been a substantial increase in the prevalence of ticks' infestation in cattle and goats in Tanzania. However, the published data on the ticks' infestation is scarce. In the present study, the proportion of tick infestation, proportion of tick spp., ticks distribution on the surface of the infested animals and mean number of the ticks' infestation in cattle and goats in a wildlife-livestock interface ecosystem at Mikunmi National Park, Tanzania, were determined. A total of 436 domestic animals were examined, including 260 cattle and 176 goats. The overall proportion of tick-infested animals was $48.6 \%$; $51.5 \%$ in cattle and $44.3 \%$ in goats whereas, the overall mean number of tick infestation was $3.9 \%$. The Rhipicephalus and Hyalomma tick spp. were the only dominant tick species present in the study region. The high proportion of tick infestation in the study region increases the likelihood of ticks and their pathogens parasitizing different vertebrate groups, resulting in pathogen spillover. Therefore, the integrated control management strategy for ticks and possibly tick-borne pathogens is required in this study region.
\end{abstract}

Keywords: Hard tick, Hyalomma, Rhipicephalus, Infestation, Prevalence, Wildlife-livestock interface, Mikumi National Park

\section{BACKGROUND}

Ticks as obligate blood-sucking ectoparasites, cause reduction in livestock weight, limit livestock production, induce anemia, cause irritation and some of the tick species cause paralysis [1]. Retained tick material and host scratching may increase the likelihood of secondary bacterial infections and reduce the quality of the hide [2]. Ticks are also the vectors and reservoirs of viruses, bacteria, protozoa, filarial nematodes that can cause diseases [3, 4].

In most areas of the wildlife-livestock interface ecosystem at Mikumi National Park, people practice traditional pastoralism, keeping large numbers of indigenous cattle and goat. Nevertheless due to scarcity of pasture land, farms, and water sources especially during the dry seasons, there is significant interaction and conflicts between the livestock keepers, farmers and wild animals straying from the reserve boundaries to the surrounding homesteads. Such interactions increase the likelihood of tick's infestation rate in the area. Several cases of tick bites, tick-borne diseases and tick infestations have been reported in the study region [3, 5]. However, no published data on the prevalence of the hard ticks' infestation from cattle and goats exists in the study region. The prevalence data of Ixodidae ticks infestation will provide valuable information to farmers and other stakeholders to improve development of tick control strategies.

The objective of this study was to determine the proportion of tick infestation, proportion of tick spp., ticks distribution on the surface of the infested animals and mean number of the ticks' infestation in cattle and goats in a wildlife-livestock interface ecosystem at Mikunmi National Park, Tanzania. The 
economic outcome can be important as tick infestation can cause severe impact in livestock. Cattle and goats are highly valuable in Tanzania and Africa in general, playing diverse roles in the livelihoods and economies of peoples and countries. Therefore, the knowledge on prevalence of ticks' infestation is important as it will help in planning, monitoring and controlling tick burden in the study region.

\section{METHODS}

\subsection{Study Site}

The study was conducted in a wildlife-livestock interface ecosystem at Mikumi National Park, Morogoro region which lies in the eastern part of Tanzania, about 285 kilometers from Dar es Salaam City. The area has typical tropical climate, with annual rainfall ranging from 600 to $1500 \mathrm{~mm}$ and average annual temperatures ranging from $20-30{ }^{\circ} \mathrm{C}$. It has exceptionally rich in flora, some of which are endemic to this district and diverse fauna making it to be unique ecosystem. In the present study ecosystem, people practice traditional pastoralism, keeping large number of indigenous cattle and goats. The movement of people and livestock beyond the national park boundary and the straying of the wild animals from the reserve boundary increase the likelihood of the ticks' infestation rate [5].

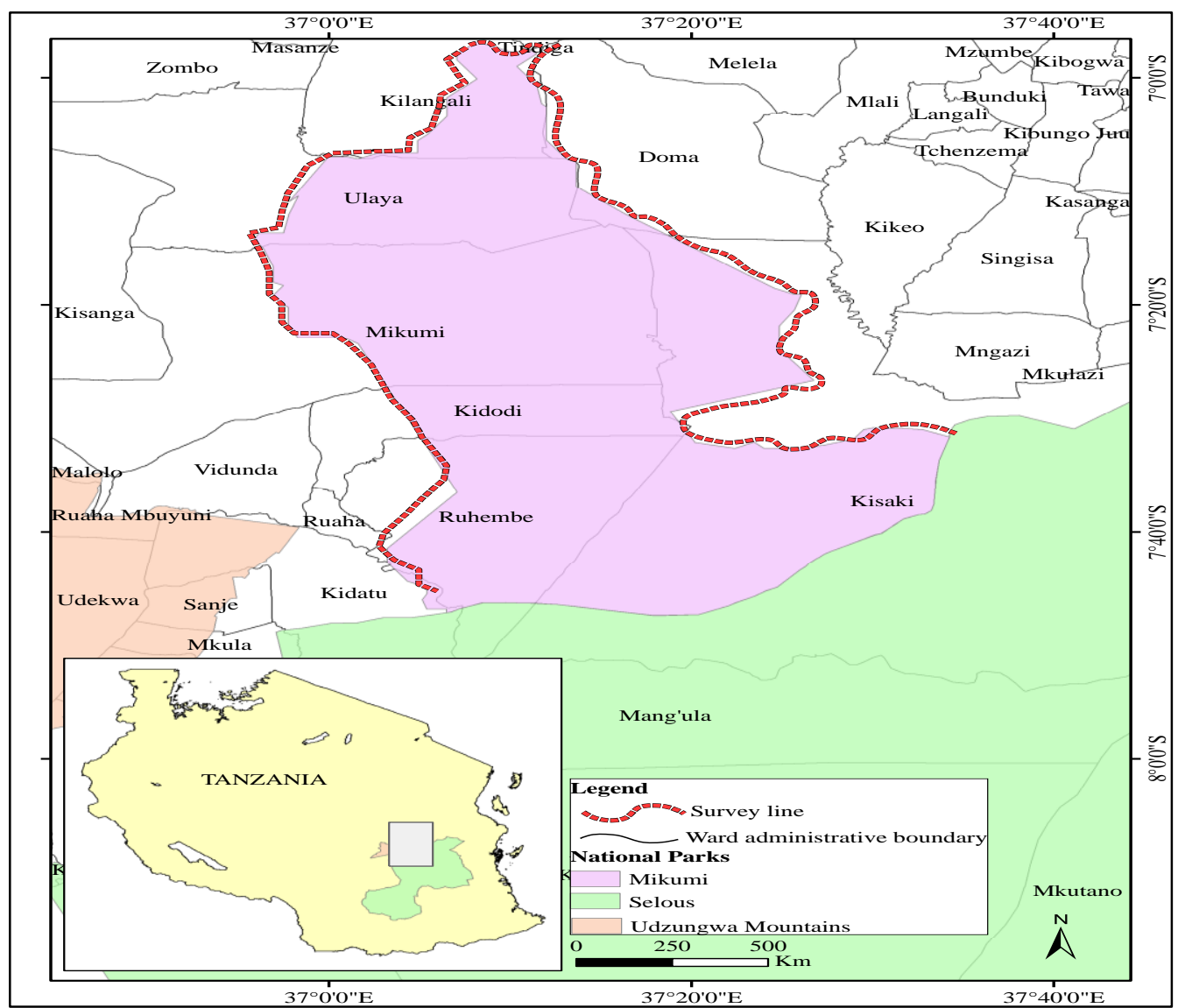

Figure1. Map showing wildlife-livestock-human interface ecosystem of Mikumi national park.

Data source; (National Bureau of Statistics GIS Data base; https://www.nbs.go.tz/index.php/en/)

\subsection{Collection of ticks}

Ticks were collected from the body of domestic animals, cattle and goats in all wards which lie at the border wildlife-livestock interface ecosystem, at Mikumi National Park. The rationale behind this approach is based on the interconnectivity of the wards bordering the park, with livestock, human, and wildlife movement across ward borders. Ticks collected from animals were removed manually and placed in sterile plastic vials [6]. Ticks were collected from 4 regions of animals body consisted of ears, neck, anal, and udder. Following collection, the ticks were transported live to the laboratory at the Entomology Unit, Department of Parasitology and Entomology, Sokoine University of Agriculture Morogoro in tubes plugged with cotton swabs. In the laboratory, the sampled ticks were 
A Survey of Hard Ticks (Ixodidae) on Cattle and Goats in a Wildlife-Livestock Interface Ecosystem at Mikumi National Park, Tanzania

washed with sterile water to remove excess environmental particulate contamination and then rinsed with $70 \%$ ethanol [7]. The washed ticks were then transferred to sterile vials and stored at $-20^{\circ} \mathrm{C}$ until processing for identification [8].

\subsection{Morphological identification of ticks}

Identification of ticks was done using morphological characteristics based on modified procedures as described by Walker et al. 2003 [1]. Sampled ticks were thawed at room temperature and rinsed once again with $70 \%$ ethanol. They were then mounted on slides and examined using stereomicroscopes with magnification up to 100x. Identification was conducted at the Entomology Unit, Department of Parasitology and Entomology, Sokoine University of Agriculture Morogoro, Tanzania. Identification of the ticks was by genus using appropriate identification keys [1].

\section{RESUltS}

\subsection{Proportion of tick infestation in cattle and goats}

Total of 436 domestic animals in 10 wards which lie at the border of Mikumi National Park were examined, including 260 cattle and 176 goats (Table1). The overall proportion of tick-infested animals was $48.6 \%(212 / 436) ; 51.5 \%$ in cattle and $44.3 \%$ in goats (Table 1 )

Table1. Number $(N)$ of animals examined and animals infested with ticks

\begin{tabular}{|l|c|c|c|}
\hline Animal & Cattle N (\%) & Goat N (\%) & Total \\
\hline Examined & $\bullet \quad 260$ & $\bullet 176$ & $\bullet 436$ \\
\hline Infested with ticks & $134(51.5)$ & $78(44.3)$ & $212(48.6)$ \\
\hline
\end{tabular}

\subsection{Proportion of tick spp. in cattle and goats}

A total of 819 ticks were collected from the cattle and goats. Among all the ticks collected, 414 were identified using morphology characters as Rhipicephalus spp., while 405 as Hyalomma spp., (Table 2) according to the identification key for adult ticks described by Walker et al. 2003. Out of 632 ticks collected from cattle, 378 (59.8\%) were identified as Rhipicephalus spp., whereas 254 (40.2\%) were Hyalomma spp. On the other hand, out of 187 ticks collected from goats in the present study, 151 (80.7\%) were identified as Hyalomma spp., and the rest were Rhipicephalus spp. (Table2).

Table2. Number $(N)$ of tick spp. collected from cattle and goats

\begin{tabular}{|l|l|l|l|}
\hline Tick genus & Cattle N (\%) & Goats N (\%) & Total \\
\hline Rhipicephalus & $378(59.8)$ & $36(19.3)$ & 414 \\
\hline Hyalomma & $254(40.2)$ & $151(80.7)$ & 405 \\
\hline Total & 632 & 187 & 819 \\
\hline
\end{tabular}

\subsection{Ticks infestation rate in outer surface of cattle and goats}

On the animal's body surface the highest infestation rate was found in the udder (38\%) and anal $(23 \%)$ in cattle, ear $(60 \%)$ and anal $(23 \%)$ in goats (Table 3$)$. On the other hand, the lowest number of ticks on animals' body surface was observed in ear (18\%) in cattle, udder $(17 \%)$ in goats whereas no tick was found on neck in goats (Table 3).

Table3. Ticks infestation rate in outer surface of cattle and goat

\begin{tabular}{|l|l|l|l|l|}
\hline Animal & Ears N (\%) & Neck N (\%) & Anal N (\%) & Udder N (\%) \\
\hline Cattle & $114(18)$ & $133(21)$ & $145(23)$ & $240(38)$ \\
\hline Goats & $112(60)$ & - & $43(23)$ & $32(17)$ \\
\hline
\end{tabular}

\subsection{The mean number of ticks in cattle, goats}

In the present study the mean number of tick infestation on cattle and goats were $4.7 \%$ and $2.4 \%$ respectively whereas, the overall mean number of tick infestation was 3.9\% (Table 4). The Rhipicephalus and Hyalomma tick spp. were the only dominant tick species present in the study region.

Table4. The mean number of ticks in cattle, goats and overall mean

\begin{tabular}{|l|l|l|l|}
\hline Category & Cattle & Goats & Total \\
\hline Animal infested & 134 & 78 & 212 \\
\hline Ticks collected & 632 & 187 & 819 \\
\hline Mean number & 4.7 & 2.4 & 3.9 \\
\hline
\end{tabular}




\section{DISCUSSION}

This study was conducted to find out the infestations rate of the hard ticks (Ixodidae) in cattle and goats in a wildlife-livestock interface ecosystem at Mikumi National Park, Tanzania. The 51.5\% prevalence of ticks in cattle observed in the present study is different from the findings of Kerario et al. 2017 [9], who reported the prevalence of $69.2 \%$ at Mara region, Tanzania. However, this finding is higher than the findings of Kerario et al. 2017 [9], who reported the prevalence of $19.1 \%$ and $11.1 \%$ at Singida and Mbeya region of Tanzania, respectively. The variations in prevalence could be due to time, habitat, ecological zones, host diversity, resistance, climate, and control measures [10, 11].

It is evident from the results in the present study that tick prevalence differed between the two animal hosts (cattle and goats), which concur with previous studies [12]. The variations in prevalence could be due to a matter of feeding behavior differences between cattle and goats, as goats are browsers [12, 13]. The observed high tick prevalence in cattle as compared to goats may also be linked with the body surface area, host genetics, and small number of goats in our study [12]. However, limited information is available about ticks' prevalence in small ruminants in Tanzania.

In the present study, two tick genera (Rhipicephalus and Hyalomma) were identified based on morphological characters. Only adult ticks were identified because immature ticks (larva and nymph) lack important morphological features required for identification [1,2]. The two genera of hard ticks identified in this study, have also been reported by other researchers in some parts of Tanzania [14, $15,16]$.The presence of similar tick species, may be associated with unrestricted cattle and goats movement from one area to another [17], which is a common phenomenon in Tanzania.

Of the two genus of tick spp. that was identified in this study, Rhipicephalus spp. was the most abundant in the study area. Our finding that Rhipicephalus spp. was the dominant tick species in the study region is in accordance with those of a local study conducted on Singida and Mbeya region of Tanzania $[14,15]$. This rapid expansion of Rhipicephalus spp. especially $R$. microplus in the field is likely attributable to the shorter life-cycle and higher egg production capacity of the Rhipicephalus spp [18]. This phenomenon has recently been reported in several African countries, including Tanzania, South Africa, and Ivory Coast [19, 20, 21]. Moreover, the ability of Rhipicephalus spp. to develop resistance to most available acaricides might also have favored its expansion at the expense of more susceptible species [22, 23]. According to Walker et al. 2003 [1], this species is widespread in tropical and subtropical regions and is considered to be the most important tick infesting livestock in the world. The high prevalence of Rhipicephalus spp., in the study area is of great interest because it is known to be a good vector of highly pathogenic Babesia bigemina and Babesia bovis, causing bovine babesiosis $[22,23]$. In addition, this spp. in terms of control management is well-known to be resistant to numerous pyrethroid and organophosphate compounds [23]. This species is also a vector of Anaplasma marginale, which causes anaplasmosis in cattle [24].

In the present study the ticks distribution on the body surface of the infested ruminants, the highest infestation was found in the udder (38\%) and anal (23\%) in cattle, ear (60\%) and anal (23\%) in goats (Table 3). On the other hand, the lowest number of ticks on animals' body surface was observed in ear $(18 \%)$ in cattle, udder (17\%) in goats whereas no tick was found on neck in goats. Most of the ticks in this study infested sites with shorter hair and thinner skin [25]. The higher tick infestations on these sites could be ascribed to the fact that ticks prefer warm, moist, and hidden sites with a good vascular supply and thin skin [26].

\section{CONCLUSION}

The high proportion of tick infestation in the study region increases the likelihood of ticks and their pathogens parasitizing different vertebrate groups, resulting in pathogen spillover. Therefore, the integrated control management strategy for ticks and possibly tick-borne pathogens is required in this study region.

\section{ABBREVIATIONS}

GIS: Geographic Information System, SIDA: Swedish International Development Cooperation Agency, SGBC: Swedish University of Agricultural Sciences Global Bioinformatics Centre 


\section{ACKNOWLEDGEMENTS}

The authors thank the Swedish Government and Swedish International Development Cooperation Agency (SIDA) for contributions and financial support. Special thanks is also extended to the University of Dar es Salaam, Tanzania, and Swedish University of Agricultural Sciences, Uppsala, Sweden, for supporting this work, as well as colleagues and researchers at the Swedish University of Agricultural Sciences Global Bioinformatics Centre (SGBC) who provided valuable knowledge and skills concerning bioinformatics. We thank the livestock keepers, village and ward leaders from each location for their help with tick collection, as well as entomologists from Sokoine University of Agriculture who assisted in tick morphological identification.

\section{FUNDING}

This work was funded by the Swedish Government through the Swedish International Development Agency (SIDA) in collaboration with the University of Dar es Salaam and the Swedish University of Agricultural Sciences.

\section{AUTHOR'S CONTRIBUTIONS}

DD designed the investigation, performed the experiments, conducted the investigation, and drafted the manuscript. MD designed the investigation, conceived the study, and revised the manuscript. JJW and $\mathrm{MB}$ conceived the study, designed the investigation, and revised the manuscript. All authors read and approved the final manuscript.

\section{ETHICS APPROVAL AND CONSENT TO PARTICIPATE}

No specific permits were required for this study. The study did not involve endangered or protected species. Therefore, the local ethics committee deemed that approval was unnecessary.

\section{PUBLISHERS Note}

International Journal of Research Studies in Biosciences remains neutral with regards to jurisdictional claims in published maps and institutional affiliations.

\section{REFERENCES}

[1] Walker AR, Bouattour A, CamicasJL, Estrada-Pena A, HorakIG, Latif AA,et al. Ticks of domestic animals in Africa: a guide to identification of species. Edinburgh: Bioscience Reports.2003.

[2] Jongejan F and Uilenberg G. The global importance of ticks. Parasitology. 2004; 129: 3-14.

[3] Estrada-Peña A, Gray JS,Kahl O, Lane RS and Nijhof AM. Research on the ecology of ticks and tick-borne pathogens, methodological principles and caveats. Frontiers in Cellular and Infection Microbiology.2013; 3:29.

[4] Yu Z, Wang H, Wang T, Sun W, Yang X, Liu J. Tick-borne pathogens and the vector potential of ticks in China. Parasitic Vectors.2015; 8:24

[5] Mansfield KL, Jizhou L, Phipps LP, Johnson N. Emerging tick-borne viruses in the twenty-first century. Front Cell Infect Microbiol.2017;7: 298

[6] Damian D, Maghembe R, Damas M, Wensman JJ, Berg M. Application of viral metagenomics for study of emerging and reemerging tick-borne viruses. Vector-borne and zoonotic diseases. 2020;20 (8), 557-565.

[7] Hasle G, Bjune G, Edvardsen E, Jakobsen C, Linnehol B, Roer JE, Mehl R, RoedKH, Pedersen J, Leinaas HP. Transport of ticks by migratory passerine birds to Norway. J. Parasitol. 2009;95:1342-1351

[8] Burger TD, Shao R and Barker SC. Phylogenetic analysis of mitochondrialgenome sequences indicates that the cattle tick, Rhipicephalus(Boophilus) microplus, contains a cryptic species. MolPhylogenetEvol.2014;76:241-53.

[9] Kerario I, Muleya W, Chenyambuga S, Koski M, Seong-Gu Hwang S and Simuunza M. Abundance and distribution of Ixodid tick species infesting cattle reared under traditional farming systems in Tanzania. African journal of agricultural sciences. 2017; 12(4): 286-299

[10] Muruthi CW, Lwande OW, Makumi JN, Runo S, Otiende M, Makori WA Phenotypic and genotypic identification of ticks sampled from wildlife species in selected conservation sites of Kenya. Vet SciTechnol. 2016; 7:1-8 
A Survey of Hard Ticks (Ixodidae) on Cattle and Goats in a Wildlife-Livestock Interface Ecosystem at Mikumi National Park, Tanzania

[11] Apanaskevich MA, Apanaskevich DA. Description of new Dermacentor (Acari: Ixodidae) species from Malaysia and Vietnam. J Med Entomol. 2015; 52:156-162

[12]Zeryehun T, Atomsa M. Ectoparasiotes infestations of sheep and goats. Eurasian Journal of veterinary science. 2012; 28: 185-189.

[13] Kaiser MN, Surtherst RW, Bourne AS. Relationship between ticks and Zebu in southern Uganda. Trop. Anim. Health. Prod. 1982;14:63-74

[14] Kerario I, Muleya W, Chenyambuga S, Koski M, Seong-Gu Hwang S and Simuunza M. Abundance and distribution of Ixodid tick species infesting cattle reared under traditional farming systems in Tanzania. African journal of agricultural sciences. 2017; 12(4): 286-299

[15] Kwak YS, Kim TY, Man SH, Lee IY, Kim HP, Mduma S, Keyyu J, Fyumagw a R, Yong TS. Ixodid tick infestation in cattle and w ild animals in Maswa and Iringa, Tanzania. Korean J. Parasitol. 2014; 5:565568.

[16]Laisser ELK, Kipanyula MJ, Msalya G, Mdegela RH, Karimuribo ED,Mwilaw a AJ, Mwega, ED, Kusiluka LJM, Chenyambuga SW. Tick burden and prevalence of Theileriaparva infection in Tarime zebu cattle in the Lake zone of Tanzania. Trop. Anim. Health Prod. 2014;46:1391-1396

[17] Moges N, Bogale B, Fentahun T. Hard Ticks (Ixodidae) Species Composition, Seasonal Dynamics and Body Site Distribution on cattle in Chilga District, Northwest Ethiopia. Asian J. Agric. Sci. 2012; 4:341345.

[18] Tønnesen M, Penzhorn B, Bryson N, Stoltsz W, Masibigiri T. Dis- placement of Boophilus decoloratus by Boophilus microplus in the Soutpansberg region, Limpopo Province, South Africa. ExpApplAcarol. 2004; 32:199-208.

[19]Lynen G, Zeman P, Bakuname C, Di Giulio G, Mtui P, Sanka P. Shifts in the distributional ranges of Boophilus ticks in Tanzania: evidence that a parapatric boundary between Boophilus microplus and $B$. decoloratus follows climate gradients. ExpApplAcarol. 2008; 44:147-64.

[20] Nyangiwe N, Harrison A, Horak IG. Displacement of Rhipicephalus decoloratus by Rhipicephalus microplus (Acari: Ixodidae) in the Eastern Cape Province, South Africa. ExpApplAcarol. 2013; 61:371-82.

[21] Madder M, Thys E, Achi L, Touré A, De Deken R. Rhipicephalus (Boophilus) microplus: a most successful invasive tick species in West-Africa. ExpApplAcarol. 2011; 53:139-45

[22] Bock R, Jackson L, de Vos, A, Jorgensen W. Babesiosis of cattle. Parasitol. 2004 ;129 (Suppl): S247-S269

[23] Baffi MA, de Sauza, GR, de Sauza GS, Ceron CR, Bonetti AM. Esterase enzymes involved in pyrethroid and organophosphate resistance in a Brazilian population of Rhipicephalus (Boophilus)microplus (Acari, Ixodidae). Mol. Biochem. Parasitol. 2008; 160:70-73

[24] Kocan KM, de La FJ, Blouin EF, Garcia JC. Anaplasma marginale (Rickettsiales: Anaplasmataceae): resent advances in defining host-pathogen adaptation of a tick-borne rickettisia. Parasitol. 2004; 129: Suppl:S285-S300

[25] Abebe R, Fantahun T, Abera M, Bekele J. Survey of ticks (Acari:Ixodidae) infesting cattle in two districts of Somali Regional State. Ethiopia. Vet. World. 2010; 3:539-543.

[26] Tadesse F, Abadfaji G, Girma S, Kumsa B, Jibat T. Identification of tick species and their preferred site on cattle's body in and around MizanTeferi, Southwestern Ethiopia. J Vet Med Anim Heal. 2012; 4:1-5

Citation: Donath Damian, et.al., A Survey of Hard Ticks (Ixodidae) on Cattle and Goats in a WildlifeLivestock Interface Ecosystem at Mikumi National Park, Tanzania. International Journal of Research Studies in Biosciences. 2020; 8(9): 35-40. DOI: https://doi.org/10.20431/2349-0365.0809005.

Copyright: ( ) 2020 Authors. This is an open-access article distributed under the terms of the Creative Commons Attribution License, which permits unrestricted use, distribution, and reproduction in any medium, provided the original author and source are credited. 